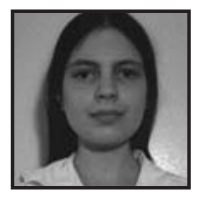

\title{
Making the Connection
}

\author{
Amelia Garmaise, Dawson College
}

\section{ABSTRACT}

In "Making the Connection", I discuss, from a secondary high school student perspective, the do's and don'ts of how to engage students in the classroom. From the little details to the larger general concepts, this article outlines some ideas that could facilitate learning, and improve the classroom environment for both students and teachers.

hading in the last bit of white space on his notes, T. glances around the classroom. Next to him, J. is staring absently at the wall. K. is talking to the girl next to her, not even bothering to keep her voice down. L. has her mathematics notes spread out on her lap, cramming for the test next period. Mr. E. drones on, oblivious or simply beyond caring.

It's the classic classroom scene, happening every day in schools everywhere. Therein lies the problem that every teacher faces: keeping students engaged. What does it take to hold the attention of the average student? Better yet, how do you draw in the apathetic student who would rather be anywhere else? What about the bored know-it-all?

In the classroom, an inherent boundary exists between the teacher and the students. Although the separation is necessary for effective teaching, certain connections need to be made for effective learning. If students feel they can talk to a teacher, they are more willing to listen to him/her. In-class discussion should be strongly encouraged. Although the old "sit down, shut up" method honestly does not work well, there is something to be said for directing the discussion. Students are more 
engaged when they feel that they can contribute to the topic, but when everyone is talking at once, there is little movement forward. Even though raising one's hand is considered on "elementary school" practice, it actually does work well when consistently enforced. Also, bland definitions can only take a person so far. Practical application makes ideas and concepts easier to remember. The use of real-world examples, such as comparing and contrasting current systems with past ones in History, or Romeo and Juliet, with a popular TV/movie couple in English are neeeded. As well, teaching material should be as modern as possible. Although the basic principles may remain the same, the methods with which textbooks handle subject matter are constantly being adapted and improved.

If at all possible, students should be given some choice of what material to learn or what major projects to take on. People in general are more comfortable when they feel that they have a measure of control, and options, even small ones, allow students to enjoy what they are learning. The difficulty of assignments should increase progressively, and should help students build on their past successes. For certain subjects, lectures are appropriate, but there is no need to be dull. Teaching, in many ways, bears much resemblance to storytelling. It takes practice, but truly dynamic, charismatic teachers can transfer information more easily to students than those who are less so. Enthusiasm, entertaining anecdotes, and even odd personal quirks make the lessons stand out in students' minds. Specific subtopics, as well as the subject in general, should be related to daily life, or connections should be made to current events.

Finally, there are a few things that are best avoided in the classroom. Although teacher/student communication is important, no one likes to be constantly grilled for answers. It makes everyone tense and many students unhappy. Monotonous routine is frankly boring and may cause students to plan ahead of time to doze off during classes. School demands homework, but quickly assigning an overwhelming workload will have students admitting defeat just as fast. If they feel that they can't cope, a considerable number probably won't even try.

In the end, there is no single panacea for engaging all students. Some students are self-motivated enough to learn themselves. The odd few are inexorably determined to ignore all involvement with the subject. Most, however, fall between these extremes. They can be engaged, given the right motivation. If teachers are willing to work towards making a real connection, their students become willing to be involved. 


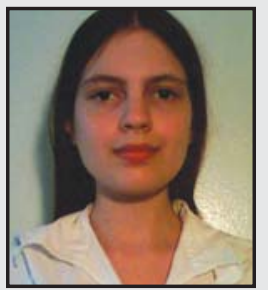

Amelia Marie Garmaise is originally from Gaspé, Quebec. She has thirteen years of experience as a full-time student. Currently living in Montreal, she is pursuing her studies in sciences at CEGEP. 